\title{
AUTENTICIDAD, MITO, LOS MODOS DE TRANSMITIR EXPERIENCIAS Y EL MODO MONUMENTAL EN LA NARRATIVA COLOMBIANA: UN ESTUDIO COMPARATIVO SOBRE LA RETÓRICA DE LA MEMORIA EN CIEN AÑOS DE SOLEDADY LA OCULTA
}

\author{
AUTENTICIDADE, MITO, OS MODOS DE TRANSMITIR EXPERIÊNCIAS E O MODO \\ MONUMENTAL NA NARRATIVA COLOMBIANA: UM ESTUDO COMPARATIVO SOBRE A \\ RETÓRICA DA MEMÓRIA EM CIEN AÑOS DE SOLEDAD E LA OCULTA
}

Florian Homann ${ }^{1}$

\begin{abstract}
RESUMEN: Tradicionalmente, los estudios sobre la memoria en la literatura colombiana se han centrado en detectar y señalar los múltiples elementos extratextuales y acontecimientos real-históricos que se han introducido en los textos. Sin embargo, son todavía escasas las investigaciones sobre las distintas formas de presentar la memoria colectiva puesta en escena en la narrativa. Por lo tanto, esta aportación realiza un estudio comparativo entre Cien años de Soledad de García Márquez (1967) y La Oculta de Héctor Abad (2014), enfocándose en la manera inovadora de la novela más reciente de contar una saga familiar, vinculada a una casa con un alto valor semántico para un colectivo y una cultura del recuerdo específica. En términos metodológicos, se abordan los dos textos aplicando una retórica de la memoria, concepto que combina los estudios de la narratología con las investigaciones sobre la memoria colectiva. En este sentido, se trata de indagar sobre la manera de narrar las historias, en concreto, si se relaciona cada uno de los dos relatos elegidos más bien con un modo asociado con la experiencia o con un modo monumental. Estos modos narratológicos sirven como categorías basadas en una distinción teórica de la memoria colectiva, entre una memoria comunicativa y una memoria cultural, relacionadas respectivamente o bien con la experiencia vivida en un pasado reciente o bien con lo mítico y épico de un pasado remoto. Las dos novelas analizadas evidencian una evolución desde lo mítico y lejano de la cultura, ficcionalizado en la obra escrita por García Márquez, hacia el horizonte del pasado reciente en la novela contemporánea de Héctor Abad.
\end{abstract}

Palabras clave: Memoria cultural; memoria comunicativa; retórica de la memoria; narrativa colombiana; experiencias.

RESUMO: Tradicionalmente, as investigações sobre a memória na literatura colombiana têm se concentrado em detectar e assinalar os múltiplos elementos extratextuais e os acontecimentos realhistóricos introduzidos nos textos. No entanto, as pesquisas sobre as distintas formas de apresentar a memória coletiva posta em cena na narrativa ainda são escassas. Portanto, esta contribuição realiza um estudo comparativo entre Cien años de Soledad, de García Márquez (1967) y La Oculta, de Héctor Abad (2014), focando na maneira inovadora do romance mais recente de narrar uma saga familiar, ligada a uma casa com alto valor semântico para um coletivo e uma cultura da lembrança específica. Em termos metodológicos, os dois textos são abordados através da análise de uma retórica da memória, conceito que combina os estudos da narratologia com as investigações sobre a memória coletiva. Nesse sentido, tratase de indagar sobre a maneira de narrar as histórias, mais concretamente, se cada um dos relatos escolhidos se relaciona mais com um modo associado à experiência ou com um modo monumental. Esses

\footnotetext{
${ }^{1}$ Doctorado en filología hispánica. Facultad de Filosofía-Estudios Románicos, Universidad de Colonia, Alemania.
} 
modos narratológicos servem como categorias com base na distinção teórica da memória coletiva entre uma memória comunicativa e uma memória cultural, ligadas respectivamente à experiência vivida no passado recente, e ao mítico épico do passado remoto. As duas novelas analisadas evidenciam uma evolução do mítico e distante da cultura, ficcionado no romance de García Márquez, para o horizonte do passado recente na novela contemporânea de Héctor Abad.

Palavras-chave: Memória cultural; memória comunicativa; retórica da memória; narrativa colombiana; experiências.

\section{La memoria colectiva y nueva narrativa colombiana}

La memoria colectiva es uno de los temas más tratados en los estudios culturales y literarios de los últimos años. Resulta fructífero aplicar los resultados y conceptos metodológicos de las investigaciones recientes para analizar en un estudio comparativo las dos novelas Cien años de Soledad (1967, en adelante CAS) y La Oculta (2014), ya que tanto García Márquez como Héctor Abad han tratado o tratan ciertos recuerdos individuales y colectivos, además de que sus textos reflejan también a nivel intratextual los mecanismos de recordar el pasado. Sus obras pueden ser leídas como medios de la memoria colectiva -sobre todo, con respecto a temas como el conflicto armado o la Violencia-, con su destacada pluralidad de los recuerdos. De tal manera, después de contestar a la cuestión de qué tipos de memoria y olvido se tratan en CAS y La Oculta, este artículo se dedica a mostrar las distintas maneras de las que se tratan los recuerdos, es decir, indagar particularmente en la forma narrativa empleada en los textos: ¿cómo se narra lo recordado?.

Las dos narraciones procesan los procesos complejos de los actos de recordar el pasado desde distintas perspectivas. Por lo tanto, para analizar de manera comparativa las relaciones entre texto narrativo y memoria en las dos novelas CAS y La Oculta se ofrecen ciertas conceptualizaciones, desarrolladas a inicios del milenio en Alemania. Estos estudios, tratando los conceptos de memoria comunicativa y memoria cultural, introducen la noción de unos marcos temporales del recordar, en horizontes cercanos o lejanos. ¿En cuál de estos marcos se puede ubicar la narración de la historia de Macondo y de la finca-casa en Antioquia? Para contestar a estas cuestiones se ofrece el concepto de la retórica de la memoria de Astrid Erll (2012) con sus distintas clasificaciones sobre las distintas formas de presentar la memoria colectiva puesta en escena en la literatura.

\section{Memoria comunicativa, memoria cultural y la retórica de la memoria en la literatura}

En general, los estudios recientes sobre la memoria colectiva subrayan en alta medida la dimensión social de los actos de recordar. De acuerdo con esto, los Cultural Memory Studies, surgidos alrededor del cambio de milenio, no son sólo una parte de la historiografía, sino que tratan temas centrales de los estudios culturales: no sólo se investiga sobre los eventos del pasado, sino también sobre el carácter de construcción procesual de los recuerdos a estos y su determinación cultural (HARTWIG, 2018, p. 361).

Una condición previa para cada tipo de memoria es la conciencia viva de los seres humanos que recuerdan algo, por lo que hay que tener en consideración las circunstancias de la sociedad en la que estos viven. En esta línea, los Cultural Memory Studies parten de dos 
suposiciones. La primera consiste en que se atribuye a la memoria un carácter de constructo, partiendo de la premisa de que un recuerdo no es un fiel reflejo de eventos pasados sino su reconstrucción individual. Esta suposición no quiere negar en absoluto la realidad de eventos históricos sino solo considerar la memoria como construida, en dependencia del presente. Según Hartwig (2018, p. 361), esta suposición lleva al segundo convencimiento básico que está constituido por la referencia al presente. Esta suposición quiere decir que la vista al pasado siempre está determinada por el presente, es decir, por la perspectiva del (colectivo) observador: la construcción del pasado sólo tiene en cuenta todo lo que es relevante para la actualidad del momento (HARTWIG, 2018, p. 361). Astrid Erll define los términos relacionados de la siguiente manera y subraya tanto el carácter procesual como el poder transformatorio de los actos recordatorios: "Más allá de las disciplinas particulares hay en gran parte acuerdo frente a que el recordar se debe concebir como un proceso, los recuerdos como su resultado y la memoria como una habilidad o estructura cambiante" (ERLL, 2012, p. 10).

Se puede concluir que el pasado no es un ente fijo y cerrado, sino que se tiene que recordar; o sea, los recuerdos a él exigen ser continuamente cultivados y recreados, de manera activa. Resulta lógico que estos recuerdos constituyan reconstrucciones en alto grado subjetivas de hechos y percepciones, que se seleccionan en dependencia de la situación en la que se evoquen, por ejemplo, en un texto literario.

Erll infiere de esta necesaria selección de distintos recuerdos que existen múltiples culturas del recuerdo con una marcada pluralidad de memorias. Esto provoca que estas memorias se manifiesten en formas de expresión de diversa índole, además de que estas manifestaciones nos indican los intereses de los sujetos selectores en este proceso complejo, por lo que los estudios sobre la memoria colectiva tratan ante todo los mencionados mecanismos:

\footnotetext{
El recordar es una operación que se lleva a cabo en el presente y consiste en reagrupar (re-member) los datos disponibles. Las versiones del pasado cambian cada vez que se evoca algo, a medida que cambian los hechos del presente [...]. El recuerdo individual y el colectivo nunca han sido por cierto un espejo del pasado, sino un indicio de gran valor informativo sobre las necesidades e intereses de los que recuerdan en el presente. En consecuencia, la investigación científica sobre la cultura del recuerdo no dirige sus intereses en primera instancia a los pasados recordados en cada evocación, sino a los presentes del recordar. (ERLL, 2012, p. 10)
}

Esto tiene consecuencias para los análisis de la literatura que se puede considerar una forma de expresión autónoma de la memoria colectiva. Los estudios enfocan en el presente del texto literario, que se ha concebido desde la perspectiva del escritor que actúa en una sociedad y que se orienta en los intereses del colectivo al que pertenece. Este fenómeno se manifiesta en una pluralidad de recuerdos observable en las novelas elegidas. La Oculta y CAS no son novelas históricas, aunque traten hechos históricos, sino que forman ficciones que tratan estos hechos en diferentes formas, además de reflejar los procesos complejos de evocar el pasado desde distintas perspectivas.

La transmisión de la memoria se caracteriza por una destacada medialidad. El historiador Jan Assmann tampoco entiende el pasado como algo natural sino como una creación cultural inexorablemente vinculada con diferentes tipos de medios a través de los que se mantiene la memoria cultural: "Lo que todavía es hoy recuerdo vivo, únicamente se transmitirá mañana a través de los medios” (J. ASSMANN, 2011, p. 50). Estos medios esenciales para la transmisión viva de los recuerdos en una sociedad pueden ser o bien medios de comunicación propiamente 
dichos o bien soportes simbólicos que son denominadas figuras del recuerdo (J. ASSMANN, 2011) o memory sites ${ }^{2}$ (RIGNEY, 2010, p. 345). Borrar estos soportes de la memoria tiene la consecuencia de olvidar lo que representan o lo que está inscrito en ellos.

El olvido es la otra cara de la medalla de la memoria. Aleida Assmann (2011, p. 396) y Elena Esposito (2010, p. 181) consensuan que se debe al olvido que los actos recordatorios se definan como procesos continuos de selección consciente, entre lo relevante y lo irrelevante, desde la perspectiva del presente. De acuerdo con estas ideas, recordar se puede traducir como recuperar algo selecto del pasado -efectivamente para no olvidar y perderlo-, vigente para el presente y para el futuro: por lo tanto, recordar significa también revivir lo pasado conscientemente en la actualidad. Así, los textos literarios frecuentemente rescatan acontecimientos silenciados y condenados al olvido para introducirlos en la cultura del recuerdo colectivo.

Con respecto a la memoria colectiva, se distingue entre varios conceptos. Basándose en los fundamentos teóricos de Jan Assmann (2011), se define, por un lado, la memoria comunicativa, relacionada con una memoria corta social, experimentada o transmitida de forma oral por los testigos directos durante un máximo de tres generaciones que se considera la memoria viva. Por el otro lado, existe una memoria cultural, abarcando varias épocas, que se define como el conocimiento compartido sobre el pasado y manifestado en ciertas instituciones. En esta memoria se basa la identidad de un grupo o de una sociedad como memoria oficial.

Esta premisa básica de que cada memoria colectiva se compone de una memoria comunicativa y de una memoria cultural, tiene consecuencias importantes para los estudios literarios. Resulta obvio que los textos literarios como CAS o La Oculta constituyen en sí unos medios que pertenecen a la memoria cultural. Al transformar los elementos tratados del mundo extratextual en materia prima para la fábula del texto literario, se insertan en la memoria cultural y se estabilizan en medios fijos. Si entran las obras en el canon literario, incluso ayudan a recordar a nivel amplio y oficial lo descrito.

Sin embargo, la materia tratada del mundo fuera del texto, se puede relacionar tendencialmente más con uno de los dos tipos de memoria descritos, es decir, memoria comunicativa y memoria cultural. El resultado es que existe una relación más estrecha del texto o bien con lo cotidiano y reciente o bien con lo épico, mítico y lejano de una cultura.

Los dos tipos de memoria se diferencian en cuanto a los cinco aspectos contenido, formas, medios, portadores y estructura temporal (J. ASSMANN, 2011, p. 47-58), de los que el último aspecto forma el punto de partida. Dado que la memoria comunicativa se ubica en el horizonte temporal de tres a cuatro generaciones, que corresponden a un lapso de ochenta a cien años y trazan un floating gap que cambia a la par con el presente, esta memoria siempre "abarca recuerdos relacionados con el pasado reciente" (J. ASSMANN, 2011, p. 50). De tal manera, contiene formas informales y escasamente modeladas o institucionalizadas, ya que se basa en la tradición oral con una comunicación cotidiana y mantiene un recuerdo biográfico cotidiano. Sin embargo, J. Assmann (2011, p. 50) concluye que esta memoria comunicativa netamente natural se ha de perder siempre a pasar el periodo de 80 hasta 100 años, después de haber desaparecido

\footnotetext{
${ }^{2}$ Se trata de un concepto desarrollado para adaptar a las dinámicas de la actualidad las ideas sobre los lugares de memoria o Les lieux de mémoire de Pierre Nora. A su vez, el concepto no se reduce a los lugares en el sentido de loci, sino que también pueden ser entes simbólicos como edificios, obras de arte o incluso textos literarios, en los que se condensan los recuerdos colectivos de una cultura del recuerdo en concreto (RIGNEY, 2010, p. 348).
} 
el último testigo directo o el último portador vivo de la tradición.

Entonces, si los recuerdos se mantienen vivos más allá de esta frontera, se encuentran en una transición a la memoria cultural, vinculada al recuerdo fundante en un pasado lejano. La memoria cultural se describe como notablemente institucionalizada y basada en ciertas objetivaciones del tipo de memory sites más bien sólidas, estrechamente vinculadas además con la identidad colectiva del grupo.

Erll relaciona los dos tipos explícitamente con dos distintos horizontes de percepción por los transmisores de la memoria, por lo que habla de dos modi memorandi, respectivamente con un horizonte cercano y un horizonte lejano del recordar (ERLL, 2012, p. 157). Así, el primer modo corresponde a lo cotidiano y realmente experimentado, mientras que el segundo modo corresponde a lo mítico y épico. Estos dos modos pueden ser aplicados tanto a los mundos de los cuales proceden los elementos que se tratan en un texto literario como a las formas en las que los textos narran lo ocurrido.

Erll (2012, p. 197) considera a la literatura en sí como una forma simbólica de la memoria cultural de determinadas comunidades, estén éstas constituidas por un país o por un grupo social; además de declarar que un texto escrito forma un medio estable de esta memoria (ERLL, 2003, p. 56). Esta investigadora resume sus argumentos por qué la literatura es un medio simbólico y muy específico de la memoria colectiva, que además tiene ciertos privilegios icónicos frente a otros sistemas simbólicos, de la siguiente manera:

A pesar de que la literatura tiene ciertos límites, su capacidad específica en la cultura del recuerdo se basa en el efecto conjunto de sus semejanzas con los procesos de formación colectiva de la memoria y de sus diferencias con las objetivaciones de sistemas simbólicos colindantes. La literatura es una forma de producción de memoria entre otras: comparte muchos procedimientos con el relato cotidiano, la historiografía y el monumento; sin embargo, crea al mismo tiempo nuevas ofertas de sentido gracias a sus cualidades sistémicosimbólicas específica. Tales ofertas de sentido se diferencian de clara de las de otros medios de la memoria. La literatura puede, de esta manera, incorporar lo nuevo y lo otro en la cultura del recuerdo. (ERLL, 2012, p. 204)

Así, determinados recuerdos se ponen en escena en la literatura, por lo que Erll (2012, p. 97) habla de escenificaciones de la memoria. Para acercarse a estas escenificaciones, la conceptualización de la novela de la memoria (ERLL, 2003), generando junto con otros conceptos $^{3}$ nuevos métodos de acercamiento a los textos literarios a través de los procedimientos propios de la narratología, se fundamenta a su vez en los conceptos de Jan y Aleida Assmann. En otras palabras, las dimensiones de la memoria comunicativa y la memoria cultural con todas sus implicaciones resultan aplicables a los análisis de los textos literarios.

Las dos obras elegidas CAS y La Oculta corresponden a este concepto de Erll, quien declara que la definición de una obra literaria como novela de la memoria depende de su

\footnotetext{
${ }^{3}$ Los conceptos de varios investigadores se ocupan de analizar la literatura que, a través de tratar la memoria, ejecuta los efectos ya mencionados de fundar una identidad colectiva en una cultura del recuerdo determinada. Otro concepto se denomina fictions of memory (NEUMANN, 2005). En su tipología, Neumann (2005, p. 208237) diferencia cuatro variantes genéricas de las ficciones de la memoria contemporáneas, de las que la novela comunitaria de la memoria es la que corresponde a CAS y La Oculta, ya que esta variante forma una memoria colectiva y específica de una comunidad determinada.
} 
recepción: los textos literarios exigen ser actualizados por los lectores contemporáneas como textos colectivos (ERLL, 2003, p. 136). Claro está que este fenómeno también depende del potencial de efecto del texto, en concreto, hay que preguntarse si este incluye elementos que afectan a un colectivo y a los procesos de concebir su memoria. En otras palabras, se trata de indagar si se pueden detectar ciertos indicios en el texto que animan los lectores a percibir una novela como novela de la memoria: "según la terminología de la narratología cognitiva, entonces de ahí se puede inferir que determinadas formas de expresión pueden inducir a los lectores a interpretar el texto literario según aquellos esquemas y frames cognitivos que también se utilizan en los procesos del recordar colectivo" (ERLL, 2012, p. 230, cursivas en el original). Entonces, los textos se convierten en medios de la memoria, naturalizados por el colectivo receptor que los consideran como tales, hecho que remite también a una determinada retórica del mismo texto: "La actualización (consciente o inconsciente) de un texto literario como medio de la memoria se puede motivar a través de una estrategia que a continuación será llamada retórica de la memoria colectiva" (ERLL, 2012, p. 230, cursivas en el original). Esta retórica de la memoria colectiva se manifiesta en cinco modos distintos, que son constituidos todos "como conjuntos de procesos textuales de representación” (ERLL, 2012, p. 231). Se trata de los siguientes modos de narraciones posibles, que pueden generarse a través de diversas formas literarias de expresión: el modo asociado con la experiencia, el modo monumental, el modo historizante, el modo antagonista y el modo reflexivo. Debido a la flexibilidad necesaria de las categorías, estos modos se entrecruzan y puede resultar la posibilidad de que a una sola obra literaria correspondan varios modos. La cuestión es cuál de estos registros domina en un texto concreto.

Para empezar desde abajo, se podrían leer las dos novelas Cien años de soledad y La Oculta según el modo reflexivo que "hace posible una autoobservación mnemocultural" (ERLL, 2012, p. 231), ya que tratan entre otros temas los procesos del recordar en la cultura colombiana.

Asimismo, se puede decir que en cierta manera ambos textos emplean el modo antagonista, ya que introducen en su cultura del recuerdo una versión nueva o renovada del pasado. Como ya se ha dicho, gracias a novelas como CAS se ha vuelto a debatir la masacre bananera en el discurso memorístico colombiano y es sumamente significante que, también a nivel intratextual, en Macondo se hace notar una competición entre la versión que defiende José Arcadio Segundo, como testigo directo, y la versión oficial. Una característica del modo antagonista es que presenta memorias de grupos marginados, para las cuales el texto toma una posición en la lucha por la hegemonía (ERLL, 2012, pp. 244-245). Esto se realiza a través de destacar ciertos recuerdos y oprimir otros, relacionados con otras culturas del recuerdo en el campo socio-cultural heterogéneo. Sin embargo, estas memorias en competencia también pueden entrar en diálogo en una obra literaria (NEUMANN, 2005, p. 210). Este fenómeno resulta de especial interés para analizar La Oculta, novela que no toma una posición tan determinada como otras novelas de Héctor $\mathrm{Abad}^{4}$, sino que deja dialogar incluso a posiciones opuestas, a través de una narración por las voces equivalentes de tres hermanos protagonistas. De estas voces, son las de las dos hermanas, además de incitar a la discusión sobre el rol de la mujer en la sociedad, que articulan respectivamente los dos polos del discurso de la memoria en Colombia. Por un lado, la figura de Eva tiene una posición liberal, emancipada y progresiva y describe en una de las escenas sobresalientes del libro su salvación del asesinato planeado por

\footnotetext{
${ }^{4}$ La obra que más evidentemente toma una posición en la lucha social es la biografía novelada El olvido que seremos (ABAD FACIOLINCE, 2006), que acusa del asesinato de su padre a los sectores conservadores, relacionados con ciertas corrientes en la Iglesia, de ultraderecha y, en especial, a los paramilitares. Sin embargo, también conviene tener cierta cautela a la hora de interpretar las intenciones memorísticas de la obra, ya que el autor no busca venganza sino justicia, a través de recordar lo ocurrido (CAPOTE, 2019, p. 42).
} 
los paramilitares. Por el otro lado, Pilar, notablemente tradicionalista y conservadora, paga silenciándolo- la vacuna de protección a estos grupos ultraderechistas, mientras que su propio hijo es secuestrado por los FARC. La imagen compleja que traza esta constelación muestra nuevos caminos en el debate, por lo que el texto literario toma una posición conciliadora en la competencia entre las distintas memorias.

Con respecto al modo historizante, no se puede hablar realmente de un empleo de este registro en la novela modelo del realismo mágico, ya que en este registro suele aparecer lo descrito como objeto de la historiografía científica: sería arriesgado afirmar que CAS con sus incontables elementos mágicos y maravillosos fuera percibido como un texto erudito, que presentara un discurso académico, formando parte de la historia oficial en el tiempo de su publicación. La Oculta, no obstante, contiene algunos elementos sueltos de este modo, puesto que trata un tipo de memoria histórica del protagonista Antonio, quien persigue dentro de la novela el objetivo de escribir la Historia de Jericó y de la población de las zonas montañosas de Antioquia. No obstante, el mismo personaje es consciente de que realiza esto como un aficionado, a través de recopilar informaciones de terceros y "no como el historiador serio y fidedigno que no soy" (ABAD FACIOLINCE, 2014, p. 106).

Sin embargo, de los cinco modos mencionados, son los primeros dos registros literarios -tratados por Erll (2012, pp. 231-239) además en un capítulo, ya que se encuentran siempre en relación- los que más interesan para aplicarlos a CAS y La Oculta. Y es que los dos modos presentados se relacionan con los horizontes temporales de percepción de lo recordado, por lo que resultan relevantes las dimensiones de la memoria comunicativa y la memoria cultural: "En el modo asociado con la experiencia, lo relatado se muestra como objeto de la memoria comunicativa cotidiana", mientras que en "el modo monumental, lo representado se muestra como objeto vinculante de un horizonte cultural amplio (nacional, religioso) de sentido, en cuanto mito de la memoria cultural vinculante" (ERLL, 2012, p. 231). De acuerdo con esto, en el primer modo mencionado, se puede observar una "preponderancia de procesos a través de los cuales el texto literario se escenifica como medio lleno de experiencia y los cuales se escenifican en la realidad representada en él como experiencia específica de una época o de un grupo social" por lo que el "acontecer ficticio tiene un efecto en cuanto experiencia vivida" (ERLL, 2012, p. 239). La sensación de que se trata de una memoria de recuerdos vivos y realmente experimentados en un pasado cercano resulta de mayor importancia para este modo literario de representación. Frente a esto, el modo monumental implica "que el texto literario se muestre como medio que contiene tradición, que configura y crea sentido" (ERLL, 2012, p. 239) y se relaciona con los procesos de la memoria cultural fundante, en un pasado remoto.

Resulta lógico que no se pueden trazar fronteras claras entre los distintos modos, en tal sentido también estos dos modos se influencian y se mezclan, incluso en la misma obra, "pues la literatura es monumental y, al mismo tiempo, se asocia con la experiencia" (ERLL, 2012, p. 230). Por lo tanto, en la literatura se pueden detectar los mencionados horizontes distintos de la percepción del pasado, que son característicos respectivamente para los dos tipos de memoria, la comunicativa y la cultural. En general, la literatura tiene el privilegio de poder jugar con estos dos horizontes al escenificar la memoria de un área cultural: "En cuanto medios de la memoria cultural, los textos literarios están en capacidad de contribuir a la construcción de mundos de sentido en el horizonte lejano de la cultura. Pero en la literatura, por ejemplo, en la literatura de generaciones, también se representa la memoria comunicativa" (ERLL, 2012, p. 230). Cas y La Oculta son dos ejemplos muy aptos para comprobar estas declaraciones, puesto que evidencian una evolución desde lo mítico y lejano de la cultura, ficcionalizado en la novela publicada a mediados del siglo XX, en pleno surgimiento del llamado boom, hacia el horizonte del pasado 
reciente en la novela del siglo XXI, escrita por Héctor Abad.

Para poder examinar una obra literaria y relacionarla con los distintos modos, existen distintos criterios, basados en la distinción narratológica entre 1) el qué: los elementos extratextuales de la memoria colectiva empleados y 2) el cómo: la manera de narrarlos. En concreto, para contestar a la pregunta de con qué modo se asocia una obra más, se puede realizar 1) un análisis de la estructura de selección y observar 2) la creación paratextual, 3) la intertextualidad, 4) la interdiskursividad, 5) la intermedialidad, 6) las estructuras de trama y los modelos de género, 7) las instancias narrativas y, por último, 8) la representación del mundo interior y 9) la representación espacial y temporal (ERLL, 2012, pp. 231-239). Así, resulta interesante preguntarse de qué sistemas reales y extratextuales vienen los contenidos de la memoria colectiva que se procesan en las dos obras, tanto en la novela de García Márquez como en la de Abad Faciolince. Contestada esta primera cuestión sobre la materia novelística, interesa indagar en la forma de representarla en el discurso textual: ¿de qué manera puede introducir la escenificación de la memoria en la literatura estos contenidos en una cultura del recuerdo?

\section{Cien años de soledady La Oculta como novelas de la memoria}

Las dos obras, aunque no sean novelas históricas propiamente dichas, se ofrecen para una lectura como novelas de la memoria, ya que incluyen incontables alusiones a los actos del recordar en sus numerosas dimensiones y permiten una autoobservación mnemocultural: ¿qué es lo que recuerdan distintos colectivos colombianos en distintas épocas y cómo lo hacen? Ambas novelas reflejan los procesos complejos del recordar, siendo un tema central los recuerdos personales de los personajes literarios, que en su conjunto forman respectivamente la memoria colectiva de Macondo y de la región del suroeste antioqueño.

Con respecto a CAS, Gerling sostiene "que la novela de García Márquez llega a jugar el rol de un 'lugar de memoria" (GERLING, 2009, p. 1). Así, Macondo como memory site constituye un soporte simbólico de la memoria colectiva de un área cultural, o sea, forma un medio de la memoria del caribe colombiano, siendo su representación fictiva.

La memoria, tanto a nivel individual como a nivel colectivo y de una región específica, constituye también el tema central en casi todas las obras del autor Héctor Abad, nacido en Medellín y muy preocupado de la comarca antioqueña. En La Oculta se negocian a nivel literario distintas memorias y discursos políticos en competencia a través de los pensamientos de los protagonistas, cuyo punto de partida es la muerte de la madre de los tres hermanos. Este acontecimiento causa muchas incertidumbres y preguntas sobre cómo seguir en el futuro con la finca del mismo nombre de la novela. Relatado al principio y así en el hic et nunc del texto, el fallecimiento provoca los recuerdos y reflexiones sobre el pasado, presentados durante el relato en múltiples analepsis, lo que vuelve a demostrar la importante relación entre pasado, presente y futuro en cuanto a cualquier acto de recordar. Las reflexiones se presentan en cincuenta fragmentos de relatos intercalados, en cada caso desde la perspectiva de uno de los tres protagonistas.

En ambas novelas, una casa representa la memoria de una familia y, a su vez, ésta representa la historia de un área cultural en Colombia, respectivamente del Caribe y de Antioquia. Otra similitud con CAS consiste entonces en la evolución de un inmueble en varias fases entre su fundación, auge, decadencia y destrucción final. En su análisis socio-cultural, Pedro Quintín-Quilez, considerando a La Oculta como el principal protagonista en esta biografía 
de la casa-finca, argumenta que esta "tiene una vida propia, de varios siglos por demás, y, tras varias décadas de expansión durante la fase de esplendor cafetero, viene pereciendo, desmembrada poco a poco, en el presente" (QUINTÍN-QUILEZ, 2019, p. 61). Así, a nivel de locus, la finca se convierte en un memory site, medio en que se apoya la memoria, no sólo de los tres personajes sino a nivel metafórico la memoria de toda un área cultural. En esta línea, Quintín-Quilez expone:

La Oculta se erige en primera instancia como un recurso de la memoria para los tres narradores que, por su intermedio, reconstruyen sus propias biografías y exponen su visión de diferentes aspectos de la vida en general (la familia, el amor, el trabajo, la sexualidad, etc.) y, en particular, de la estructura de propiedad de la zona de colonización occidental antioqueña, la violencia sufrida en las últimas décadas y el desarraigo de la región. (QUINTÍNQUILEZ, 2019, p. 62)

La recomposición de los recuerdos individuales puede ser interpretada, por lo tanto, como ejemplificadora de una memoria colectiva, o sea, una memoria compartida con otros individuos, teniendo en cuenta que se puede leer La Oculta como "una reconstrucción ficcional de la historia de la parte sombría del acontecer local y regional que su autor sacaría a la luz, el develamiento de la parte oscura de la historia de este país” (QUINTÍN-QUILEZ, 2019, p. 62).

Más allá de este vínculo estrecho entre una casa y el destino de un colectivo, existen notables similitudes entre las dos novelas, con respecto a la memoria, sus medios y figuras transportadoras. Semejante a las siete generaciones de los Buendía, los tres protagonistas de La Oculta, además de representar la propia familia del autor ${ }^{5}$, simbolizan un colectivo notablemente heterogéneo, con distintas opiniones e interpretaciones de sus recuerdos. Ante todo, se refleja la heterogeneidad en las dos hermanas que, como ya se ha dicho, representan caminos sociales y corrientes de pensamiento prácticamente opuestas ${ }^{6}$. De nuevo se evidencia que los recuerdos y sus interpretaciones dependen en alta medida de la perspectiva del observador del pasado, de sus valores y normas: según los Cultural Memory Studies, no existe realmente una verdad histórica sino sólo las distintas interpretaciones de la historia. En el caso de un texto literario, esta perspectiva se puede -con cierta cautela de no caer en la trampa del biografismo- relacionar con la posición interpretativa de su escritor. Las influencias biográficas de los dos autores se hacen notar, entre otros detalles, en los apellidos de ciertos personajes. Mientras que García Márquez da el apellido Iguarán de su propia abuela a la protagonista Úrsula, en La Oculta aparece el primer apellido del autor con respecto a los colonos del siglo XIX y lo lleva la esposa del primer Ángel que pobló las nuevas tierras: "Isaías Ángel y Raquel Abadi fueron de los últimos en apuntarse a la lista del Cojo" (ABAD FACIOLINCE, 2014, p. 110). El personaje Antonio, quien se interesa por aquellos horizontes fundacionales de la memoria, explica que ambas familias descendieron de judíos conversos y modificarían sus apellidos, así que el apellido Abad procede de Abadi y Ángel de Santangel: "No sé si éramos judíos, pero de sangre muy limpia no parece que fuéramos, pues teníamos nombres de judíos y

\footnotetext{
${ }^{5}$ En cierta manera, se podría relacionar la figura de Antonio con el autor, con respecto a su relación como único varón con las dos hermanas: la relación del autor, crecido en un ámbito notablemente femenino, con sus cinco hermanas está descrita en El olvido que seremos.

${ }^{6}$ También se puede preguntar si el hecho de que son dos hermanas que presentan las distintas posiciones políticas puede ser entendido como una alusión a que se trata, hablando de la lucha armada en Colombia, de un tipo de guerra civil.
} 
apellidos de conversos" (ABAD FACIOLINCE, 2014, p. 37). La Oculta y las otras fincas descritas, todas realmente existentes, mantienen además un vínculo con el documental Carta a una sombra (2015), dirigido por la hija del autor Daniela Abad y Miguel Salazar, y la novela El olvido que seremos, en la que se basa el documental. En esta biografía novelada de Héctor Abad sobre su padre aparece brevemente la mencionada reflexión sobre el posible origen judío de la familia, al que le recuerda el padre del Yo ficcionalizado al informarle "que muchos antioqueños -y posiblemente hasta nosotros mismos- teníamos sangre judía” (ABAD FACIOLINCE, 2008, pp. 27-28). En el caso del autor antioqueño, a pesar de que no son los mismos protagonistas quienes llevan su apellido, muchas referencias remiten a la familia del autor: "La mayor parte de las referencias extratextuales son reales y en los tres personajes de la obra se diluyen las personalidades de Abad Faciolince, sus hermanas y su madre" (CAPOTE, 2019, p. 47).

En cuanto a cuestiones ideológicas y la correspondiente interpretación de acontecimientos históricos, los autores de ambas novelas se pueden considerar defensores de las ideas de izquierda política (SIEBENMANN, 1989, p. 66). Sin embargo, resulta interesante que a nivel literario no se nota realmente un enaltecimiento de una posición única, sino que hay distintos ejemplos en los que se codifican ciertas dudas. Después de haber iniciado sus 32 levantamientos en los conflictos bélicos desarrollados en el mundo fictivo macondino, es el coronel Aureliano Buendía, en principio liberal, quien se muestra obviamente decepcionado de la política que ha perseguido. En la finca La Oculta es el personaje Jacobo, padre de los hermanos y liberal convencido, quien se demuestra notablemente decepcionado del lado izquierdista más radical e incluso se enferma por el secuestro de su nieto Lucas por los guerreros de la FARC, durante el cual "pedía a sus amigos de izquierda que le ayudaran", sin éxito: "E insultaba a los guerilleros a los gritos, por la calle, borracho, y se insultaba a sí mismo con los mismos epítetos con que los insultaba a ellos" (ABAD FACIOLINCE, 2014, p. 227). Resulta obvio que también el texto de La Oculta evita adoptar posiciones ideológicas extremistas y unilaterales, a favor de enseñar unos "derroteros para la sociedad colombiana más abiertos y permisivos, alejados de la intransigencia ideológica que, en caso extremo, alimentó la violencia de paramilitares o guerrilleros" (FRAGERO GUERRA, 2018, p. 314).

En definitiva, no hay duda de que ambas obras mantienen relaciones importantes. Para indagar sobre las relaciones entre identidad cultural, memoria y literatura, el fenómeno de la intertextualidad resulta crucial. Lachmann (1990, p. 35) declara que la intertextualidad constituye la memoria de un solo texto y de toda la literatura de su área cultural. Así, un texto se basa en los textos a los que recuerda, a través de retomar elementos de los anteriores. Asimismo, estos pretextos se convierten, mediante la relación intertextual, en textos fundantes de una memoria cultural. Los textos posteriores también se relacionan con los fenómenos implicados en los procesos de construir una memoria cultural, ya que las "obras literarias cobran autoridad a partir de la literatura anterior, al relacionarse con los textos canónicos y clásicos" (ERLL, 2012, p. 234). Resulta lógico que los juegos intertextuales ayudan a articular un discurso literario a lo nacional.

Capote (2019, p. 46) anota que el elemento nacional y típicamente colombiano en una novela depende de lo que se puede vender como tal en el mercado global: hoy es mayoritariamente la violencia de sicarios y narcotraficantes, mientras que en la época del boom el elemento exótico de América Latina se basaba en lo mágico y maravilloso percibido como lo real; anteriormente, en el siglo XIX, la descripción de la tierra y variedad regional formaba el elemento particular en las literaturas de los países latinoamericanos. A pesar de que el macondismo frecuentemente quede parodiado en la nueva narrativa colombiano -también con un juego intertextual irónico en otra obra del mismo autor como lo es el relato 
Rebus de la colección Basura (ABAD FACIOLINCE 2000)-, La Oculta es de todas las obras escritas por Héctor Abad la más representativa para un colectivo y el área cultural en que viven sus miembros, ya que "se centra de manera específica en el retrato de lo nacional, y lo local superando maniqueísmos sobre lo identitario y haciendo homenaje a la tierra de su región“ (CAPOTE, 2019, p. 47). Esta referencia a un área cultural, sus tradiciones y su memoria se realiza, sobre todo, a través de describir el apego de los habitantes a la tierra y la naturaleza local con múltiples alusiones a flora y fauna autóctonas, al relatar "la amenaza del terreno paradisíaco, sus plantas, sus flores, sus comidas y sus frutas, en primer lugar, por los movimientos guerrilleros y paramilitares, y más adelante, por la especulación de la tierra y la destrucción de espacios naturales" (CAPOTE, 2019, p. 48). Los espacios naturales se convierten en verdaderos memory sites, el ejemplo idóneo para esto constituye el lago al lado de la finca, que tiene una decisiva función memorística, además de conmemorar los cinco ahogados en él, ya que el agua oscura salva la vida a Eva en su huida de los paramilitares. Su destrucción al final de la novela por el acto de secarlo equivale a dejar caer en olvido simbólicamente muchas historias relatadas. Debido a las relaciones tanto con lo local-identitario como con ciertos aspectos autobiográficos, "el lector tiende a leer el último trabajo de Abad Faciolince como una continuación de la saga y la memoria familiar" (CAPOTE, 2019, p. 47). Esta recepción ubica La Oculta muy cerca de la saga de los Buendía. Es sumamente interesante que existe una relación con la venta del texto literario a nivel global y su publicidad, puesto que, en el texto de portada de la traducción alemana (ABAD FACIOLINCE, 2018), se anuncia a La Oculta como la respuesta de literatura mundial a Cien años de Soledad.

El olvido, fenómeno polifacético, es también esencial en ambas obras. Un tipo específico de olvido, en directa relación con los fenómenos vinculados a la identidad cultural, se encuentra en CAS en el episodio de la peste del insomnio, que se puede comprender fácilmente como alusión al peligro de una pérdida de identidad cultural, debida a la carencia de una memoria colectiva cultivada: "Quería decir que cuando el enfermo se acostumbraba a su estado de vigilia, empezaban a borrarse de su memoria los recuerdos de la infancia, luego el nombre y la noción de las cosas, y por último la identidad de las personas y aun la conciencia del propio ser, hasta hundirse en una especie de idiotez sin pasado" (GARCÍA MÁRQUEZ, 2007, p. 56). Esto constituye un tema crucial a todos los niveles de la novela, ya que la peste afecta también a los macondinos y, simbólicamente, a los latinoamericanos en general. Por lo tanto, de la famosa cita, resumiendo su viaje a Aracataca en 1952, de que Gabo quería contar "todo el pasado de aquel episodio" (GARCÍA MÁRQUEZ apud GARCÍA DE LA CONCHA, 2007, p. lx), se puede interpretar la narración en CAS como un intento de luchar contra este olvido, en el sentido de descuido de la memoria de su área cultural, incluyendo la recuperación de lo oficialmente olvidado. El apocalipsis al final de la novela consigue una nueva función simbólica importante con respecto a esta tensión entre recordar y olvidar.

También en La Oculta, el olvido es un elemento omnipresente. Si partimos de que la finca es un medio simbólico del recuerdo, un auténtico memory site a nivel familiar, su consumación como finca autónoma en el final de la novela, equiparable al fin del mundo macondino, simula también el olvido de todo esto a lo que incita a recordar. Así, la puesta en escena literaria es un método preventivo para que no caigan en olvido los sucesos narrados. Para los Ángel, la amenaza de su terreno implica simbólicamente el peligro de un olvido de la memoria familiar y de la propia identidad, lo que queda reflejado en el encargo del padre a Pilar de encargarse de que nunca se venda la finca bajo ninguna condición (ABAD FACIOLINCE, 2014, pp. 227-229), justo antes de morirse: 
Y mi papá lloraba igual que yo, en silencio, porque nos estabamos despidiendo para siempre, y él me estaba pidiendo que me apegara más a un maldito pedazo de tierra que a una persona. Me estaba pidiendo que soportara, por La Oculta, la muerte de él y hasta la muerte de mi hijo. Yo no lo entendía bien, francamente, aunque ahora que estoy vieja lo entiendo mucho mejor. (ABAD FACIOLINCE, 2014, p. 228)

Esta relación se puede ampliar a la idea de que destruir lo particular de la región puede implicar una pérdida de la memoria e identidad regional; en el texto, la peculiaridad identitaria del paisaje es extinguida cuando la nueva urbanización de lujo convierte el lugar en un tipo de ciudad sin encanto:

Los nuevos dueños de las parcelas empezaron a construir sus casas: mansiones enormes en estilos distintos: californiano, Bauhaus, colonial, narco-mafioso. Casi todas tienen piscinas, prados, caballerizas, jacuzzis al aire libre, jardines diseñados. Desde la parte de atrás de la casa ya no veo el paisaje abierto que mi memoria recuerda, las fotos muestran y mis ojos añoran: frente a mí hay varios techos de tejas de casas inmensas, y piscinas azules, falsas, todo rodeado por cercos altos de plantas exóticas, con púas, y por la noche chorros de luz que rompen la penumbra e iluminan jardines sosos, geométricos. (ABAD FACIOLINCE, 2014, p. 328)

Estas consideraciones favorecen recurrir para un estudio comparativo al concepto de la retórica de la memoria presentado, ya que conceptúan cada una de estas obras como un lugar de tensión entre la historia, la memoria y el olvido.

\section{1 El modo monumental de narrar el relato en Cien años de soledad}

Ya la etiqueta del realismo mágico invita a considerar el relato de CAS como una combinación entre un realismo histórico y un mito legendario en el horizonte lejano de una cultura, en el que lo mágico se considerado como algo cotidiano ${ }^{7}$. Un análisis exhaustivo de la retórica de la memoria específica de CAS (HOMANN, forthcoming) ha dado los resultados que domina el modo monumental sobre el modo asociado con la experiencia. Sin embargo, se pueden detectar características asociadas con ambos modos, lo que hace notar la mezcla compleja de las técnicas narrativas a las que recurre García Márquez.

Por un lado, el texto recuerda múltiples acontecimientos oficialmente olvidados, que quedaban latentes en la comunicación cotidiana, por lo que se trata de la escenificación literaria de una memoria oral comunicativa. Por el otro lado, al emplear en su retórica de la memoria mayoritariamente el modo específico mencionado, vinculado a lo monumental, la narración concede a la experiencia revivida un notable sentido cultural. En otras palabras, mediante la modelación literaria, la ficcionalización y las complejas estrategias de mitificación, CAS convierte los recuerdos de la memoria cotidiana del área cultural del caribe colombiano en una memoria cultural. Esta memoria se caracteriza por cierta atemporalidad y universalidad, por lo

\footnotetext{
${ }^{7}$ Existe consenso de que el realismo mágico en general representa una síntesis dialéctica entre la ficcionalización mágico-mítica de una materia, cuyo punto de partida constituyen datos históricos, y una determinada realidad recordada en la memoria colectiva (WEHR, 2003, p. 385).
} 
que se relaciona con la identidad colombiana y latinoamericana. Gracias a conseguir esta atemporalidad y universalidad a través de las técnicas de narración, la novela es capaz de desligar las experiencias de los cuerpos transmisores, vivos durante un lapso de tiempo limitado, para transformarlas en la épica de todo un continente.

Antes de mencionar brevemente los puntos más llamativos de cada aspecto de la retórica de la memoria, se puede resumir, con respecto a la materia fabulística y la forma de modelarla, que los elementos proceden de una memoria comunicativa ${ }^{8}$, no obstante, debido al modo monumental de presentarlos, se convierten en mitos culturales. En tal sentido, los paratextos destacan lo épico y cuasi sagrado que contiene CAS como Biblia de América Latina, por lo que su recepción se guía por una lectura que corresponde a los textos ficcionales sobre un origen lejano. Si nos fijamos en el aspecto intertextual, es efectivamente la Biblia uno de los pretextos más adoptados. En general, el fenómeno de la intertextualidad se vincula con el modo monumental por concederle una considerable autoridad cultural tanto a las obras citadas como a las que citan los clásicos, por lo que se puede observar una cadena de influencias culturales: un texto clásico como CAS incorpora otros textos anteriores y se convierte, a su vez, en intertexto para obras posteriores que refieren a la tradición literaria. Gracias a las redes intertextuales con las otras obras, una novela como CAS se puede convertir en un verdadero monumento de la tradición cultural. A nivel de la narración y su lenguaje, la dialéctica interdiscursiva entre oralidad y escrituralidad crea un discurso literario muy complejo, que se caracteriza por contener elementos de lo cotidiano y de lo épico (DÜSDIEKER, 1999, p. 80). El aspecto intermedial del texto también sitúa a CAS entre los mundos de lo cotidiano comunicativo y lo cultural. Asimismo, las estructuras de trama y los modelos de género constituyen factores de los que se puede desprender si una narración tiende más hacia el modo asociado con la experiencia o hacia el modo monumental. Según Erll (2012, pp. 235-236), los high mimetic modes, caracterizados por narraciones sobre héroes sobrenaturales, como lo es la épica, se relación con el modo monumental: en Macondo, se evidencia este elemento épico en la descripción de héroes legendarios como lo son el fundador José Arcadio y sus hijos, tanto el mítico coronel Aureliano Buendía como el sobrehumano José Arcadio, con sus prodigiosas fuerzas y exageradas potencias sexuales.

Un factor narratológico de extraordinaria relevancia está constituido por las instancias narrativas. La perspectiva heterodiegética de un narrador con una focalización cero implica ninguna limitación acerca de las informaciones sobre lo que está contando. Gracias al conocimiento total de lo sucedido, la voz narradora de CAS se puede considerar una authorial voice, usando los términos de Lanser (1992, pp. 18-21). Debido a esta autoridad de la voz, BellVillada la compara con los transmisores omniscientes de las epopeyas en ciertas culturas orales:

The book came written with utter authority, had the voice of a wise yet involved and caring speaker who -like an African griot, or a super narrator of folk epic and fairy tale, or an ancient Biblical scribe- truly knows everything about and everyone in a society, from its high notables to its sullen rejects, and moreover sees fit to tell the whole world about them. (BELL-VILLADA, 1985, p. 18)

Este narrador notablemente auctorial de CAS oscila "entre cronista y oráculo, entre

\footnotetext{
8 Esta memoria se caracteriza por una extraordinaria tradición oral, ya que muchos contenidos le fueron transmitidos a Gabo por sus abuelos, que se pueden considerar testigos directos de lo ocurrido, por ejemplo, en la Guerra de los Mil Días. Esto concede una considerable inmediatez a la transmisión de las experiencias.
} 
omnisciencia y divinidad" (DE TORO, 1992, p. 103). Por lo tanto, esta voz casi divina se ofrece para narrar en el modo monumental:

Para la transmisión narrativa de la memoria cultural son especialmente apropiadas las instancias narrativas omniscientes [...]. Tales instancias narrativas tienen algunos privilegios: puesto que no son en sí figuras de la historia, sino que están por encima de ella casi de manera celestial, tienen una visión general del tiempo y del espacio, de las figuras actuantes y de sus motivos. Parecen estar tan poco involucrados en los asuntos cotidianos de la vida representada como lo están los portadores de la memoria cultural. (ERLL, 2012, p. 236)

Debido a la visión colectiva que representa de Macondo, la voz narativa en CAS puede denominarse communal voice (NEUMANN, 2005, p. 161): aprovechando este privilegio de hablar por todos los macondinos, funda una identidad colectiva. Además, se articula desde una perspectiva específica, que Düsdieker $(1999$, p. 82) describe como la voz salvaje del propio pueblo y que se caracteriza por un conocimiento destacado del mundo interior de los personajes. Como criterio de una retórica de la memoria específica, la representación del mundo interior ofrece ciertas técnicas que ayudan a la literatura, "a través del uso de su privilegio de representación absoluta del mundo interior" (ERLL, 2012, p. 238), a desligar las experiencias de los individuos para convertirlas en objetos de la memoria cultural. Debido a la universalización de lo recordado en Macondo, la retórica de la memoria aplicada en CAS tiende evidentemente hacia el polo de lo monumental, ya que convierte la percepción individual en experiencias generales y fundacionales de todo un colectivo. La representación espacial y temporal también ayuda a ubicar lo narrado en un horizonte cercano o lejano de la cultura, según se usen deícticos más bien relacionados con lugares y tiempos o bien inmediatos o bien míticos. Los escasos datos concretos proporcionados le conceden la mencionada atemporalidad y, consiguientemente, la notable universalidad a Macondo. Se puede resumir de los análisis narratológicos realizados por De Toro (1992) que el tratamiento temporal de CAS, con sus laberintos de numerosos ciclos narrativos y permutaciones temporales explícitas, convierte la novela en una narración épica de mitos fundadores. Este tratamiento refuerza la atemporalidad, teniendo en cuenta que la única mención de un dato relativamente concreto para orientarse en el tiempo es la del siglo XVI (GARCÍA MÁRQUEZ, 2007, p. 29). Este dato representa en los recuerdos colectivos un horizonte temporal lejano, de los antecedentes lejanos de los protagonistas, o sea, una prehistoria, "varios siglos" o concretamente unos "trescientos años" (GARCÍA MÁRQUEZ, 2007, p. 30) antes de la fundación de Macondo. A nivel de espacio, la ubicación del microcosmo Macondo tampoco está definida de manera exacta, aunque se pueda situar en el caribe colombiano. En este sentido, el paratexto de la edición conmemorativa de la RAE declara sobre la ciudad fictiva: "arraigada en un rincón de América, en ella palpitan experiencias universales de humanidad: Macondo es un lugar que contiene todos los lugares" (RAE apud GARCÍA MÁRQUEZ, 2007, p. ix). De tal manera, se forma un memory site que dispone de una validez simbólica general.

En conclusión, la forma de la narración corresponde más a un modo monumental para transformar los múltiples elementos de la memoria comunicativa, que el autor escucharía de viva voz de sus propios abuelos y demás parientes, en relatos literarios épicos. Las técnicas narrativas empleadas tienen los efectos de abstraer estos elementos y mitificarlos en un pasado absoluto de la memoria cultural. Así, los recuerdos contados, desligados de los cuerpos 
transmisores inmediatos, se perciben más bien en un horizonte remoto, como pertenecientes a un mundo "prehistórico" (GARCÍA MÁRQUEZ, 2007, p. 9), creando una verdadera epopeya del origen y del mito fundador de Macondo.

\subsection{La evolución de la retórica de la memoria hacia lo experimentado en La Oculta}

La retórica de la memoria aplicada en La Oculta llama la atención por tender notablemente hacia el modo asociado con la experiencia y por reforzar, de tal manera, la sensación de cierta autenticidad de los recuerdos puestos en escena en la ficción. Sin embargo, también en esta novela se hace notar que se aplican estrategias literarias relacionadas con ambos modos de narrar, lo que enriquece el estilo narrativo por la hibridez compleja de las técnicas empleadas.

Con respecto al primer aspecto mencionado, sobre la cuestión de qué elementos extratextuales se han elegido, se puede decir que estos provienen de una memoria comunicativa y que son, por tanto, asociados con la experiencia vivida por los habitantes de determinadas regiones de Colombia, ante todo del departamento de Antioquia con su capital Medellín, tratada desde los años 80 y 90 en múltiples obras literarias como urbe tremenda, conocida por una extrema violencia. También las zonas rurales constituyen un tema literario, tratando las consecuencias de la Violencia. Las experiencias y los acontecimientos experimentados forman, por lo tanto, una memoria cotidiana a un pasado reciente, desde la perspectiva de la época de la creación, publicación y recepción de La Oculta. En otras palabras, los elementos narrados de la fábula proceden de una memoria en un horizonte temporal próximo, por lo que, en este caso, "la literatura tiene además un significado en cuanto medio de la memoria comunicativa allí donde se escenifican experiencias históricas traumáticas de un pasado cercano [...]" (ERLL, 2012, p. 232). El tratamiento de experiencias traumáticas de un pasado inmediato se puede transferir también al nivel individual y biográfico del escritor de la novela, ya que se tematiza, entre otras cosas, la ejecución (intentada) de un asesinato por un grupo paramilitar de la ultraderecha, aludiendo al homicidio del propio padre del autor, descrito ya más detalladamente en el El olvido que seremos. La autenticidad de muchas referencias extratextuales y los paralelismos con los aspectos autobiográficos le conceden a la novela cierta verosimilitud de haber experimentado realmente lo narrado. No obstante, las tres figuras protagonistas también se pueden considerar, gracias en parte a su heterogeneidad, como representativos para la población colombiana general en los siglos XX y XXI. A pesar de sus diferencias en su forma de pensar, todos sufren bajo la situación y padecen respectivamente un destino en cierta manera típico para la población en general: Antonio se encuentra, como millones de colombianos, en el exilio en los EEUU; Eva, notablemente liberal, queda casi asesinada por paramilitares y Pilar, cuyo hijo es secuestrado por los guerrilleros de la FARC, destaca en cambio por su pensamiento conservador. Se trata de acontecimientos que en su conjunto no son específicos de un grupo social, sino que proceden también de un horizonte amplio de sentido cultural nacional. En resumen, los elementos proceden de un ámbito relacionado con la memoria comunicativa de un colectivo amplio.

En relación con esto, es significativo que los paratextos, sobre todo los editoriales, suelen destacar, por un lado, el episodio de la huida de Eva y, con ello, la autenticidad vivida de lo relatado. Por el otro lado, se suele subrayar también la relación entre el destino de la familia, del pueblo y del país entero y, con esto, mayoritariamente en el extranjero, el vínculo con la tradición literaria, a través del ya mencionado anuncio como respuesta a la novela colombiana 
más famosa. De acuerdo con esta relación, Juan Ángel Juristo opina en su reseña del libro que La Oculta consiste en dos partes distintas que se manifiestan, por un lado, en lo ancestral que se rememora y, por el otro lado, en las voces llamativamente modernas que articulan los pensamientos y que remiten al esfuerzo individual progresivo para avanzar hacia el futuro. Este crítico deduce de la presencia de varios elementos mítico-épicos en el texto que "incluso hay trozos que se quieren herederos de Cien años de soledad" (JURISTO, 2016, p. 112). Sin embargo, mientras que los paratextos de la novela de García Márquez subrayan el vínculo con la epopeya, esta respuesta no se presenta como necesariamente afirmativa o reproductora sino como notoriamente renovadora y adaptada a la actualidad: a través de las voces netamente modernas, expone ciertos recuerdos colectivos del pasado en un horizonte cercano de percepción.

El tercer aspecto de análisis es el de la intertextualidad. En general, Héctor Abad juega con frecuencia con las reflexiones sobre las teorías literarias, de las que la intertextualidad es una de las conceptualizaciones más relevantes. En La Oculta también se encuentran múltiples momentos en los que otros textos literarios juegan un papel decisivo y, con ello, numerosas obras referidas; por ejemplo, justamente antes del ataque de los paramilitares Eva lee un libro anotado por su padre, reflexionando exhaustivamente sobre un comentario suyo (ABAD FACIOLINCE, 2014, p. 51). No se puede ignorar que también la novela de García Márquez queda explícitamente mencionada; en este caso, no se trata de ninguna parodia, como suele ser el caso en muchas narrativas nuevas distanciándose del macondismo, sino de una referencia a la repetición de los nombres en la familia protagonista por la comparación con los Aurelianos Buendía (ABAD FACIOLINCE, 2014, p. 286). Así, CAS se convierte en un fundamento intertextual ${ }^{9}$.

El factor de la interdiscursividad se puede asociar con ambos modos de la retórica de la memoria (ERLL, 2012, p. 232). Debido a que no se encuentra ninguna instancia heterodiegética en la narración, sino que el discurso narrativo se articula a través de tres voces distintas, que a su vez presentan múltiples discursos heterogéneos más, tenemos el caso de una notable multiperspectividad con diversos discursos y registros. Y es que el uso de distintos registros puede conceder a la narración un grado alto de referencia a los discursos extraliterarios en una sociedad, ya que ciertas peculiaridades lingüísticas como el uso de formas coloquiales del habla o expresiones específicas de un grupo ayudan a ubicar la narración en el ámbito cotidiano y corresponden al modo asociado con la experiencia (ERLL, 2012, p. 235). El discurso de La Oculta se articula a través de monólogos interiores con varias citas de conversaciones orales con voces intradiegéticas: por ejemplo, se citan directamente las conversaciones de los colonos del siglo XIX (ABAD FACIOLINCE, 2014, pp. 108-109) o se transcribe la forma coloquial de expresarse la abuela de los protagonistas, usando abundantemente la expresión cariñosa mijita. Fragero Guerra (2018, pp. 322-323) señala la llamativa presencia de refranes, expresiones coloquiales y vocablos específicos del lugar en la novela. En general, la tensión entre un discurso marcado por la oralidad, como medio inestable de la memoria comunicativa en horizontes cercanos, y uno por la escritura, capaz de conservar los recuerdos por distancias ilimitadas como medio estable relacionado con la memoria cultural, implica unas consecuencias complejas para un texto literario y su grado de inmediatez y verosimilitud de lo presentado. Según Goetsch (1987, pp. 12-13), la narración fingidamente oral da vida a los elementos narrados en el medio escrito. Con respecto a la distinción entre los distintos tipos de memoria colectiva, un relato oral fingido con su simulación de la narración oral ubica lo narrado, por lo tanto, en el horizonte

\footnotetext{
${ }^{9}$ Un estudio detallado sobre la manera como el autor contemporáneo juega con esta relación intertextual en concreto, a través de las múltiples alusiones detalladas, ofrece una perspectiva de investigación para el futuro.
} 
cercano y en el pasado inmediato. Carmen Fragero Guerra sostiene que la narrativa oral literaria aplicada en el discurso de esta novela en concreto persigue efectivamente el objetivo de "mostrar la realidad cotidiana, de ahí el intento por reflejar la lengua oral” (FRAGERO GUERRA, 2018, p. 321). Otro tipo de lenguaje específico es el usado por Los Músicos, el grupo paramilitar que amenaza de asesinar a Eva, que se articulan por escrito en un español plagado de falta y errores, provocando una impactante sensación de incultura que encoleriza a Eva (ABAD FACIOLINCE, 2014, p. 26). El contenido de la carta de amenaza se encuentra como medio exterior inserto en el texto.

Por lo tanto, en cuanto a la intermedialidad se puede decir que se encuentran diversos medios, en sus distintas dimensiones, en la novela. Los medios de comunicación contemporáneos, como por ejemplo las video llamadas por Skype entre Antonio y su madre (ABAD FACIOLINCE, 2014, p. 11), ayudan a referir al presente del siglo XXI y marcan una diferencia frente a la atemporalidad de CAS. En La Oculta, todo el pasado que se recuerda y narra tiene una relevancia inmediata para la situación actual de los protagonistas, teniendo en consideración la necesidad de decidir qué hacer con la finca. Esto se puede decir también del libro dentro del libro que Antonio quiere escribir sobre la historia de la fundación del pueblo (ABAD FACIOLINCE, 2014, p. 273), ya que los datos y fragmentos extraídos forman parte de su argumentación personal en el texto narrativo. La consiguiente plurimedialidad de la novela se relaciona con ambos modos retóricos: la memoria comunicativa se manifiesta en los medios contemporáneos y en parte efímeros, relacionados con la oralidad, mientras que el modo monumental está presente en la novela gracias a fijar por escrito las indagaciones sobre la historia fundacional del lugar.

Las estructuras de trama y los modelos de género, sexto aspecto mencionado por Erll (2012, pp. 235-236), se asocian con los distintos géneros literarios correspondientes -por ejemplo, la epopeya o una autoficción- por los ámbitos de los que proceden las figuras cuyas vidas imitan los textos. Según la clasificación de Frye (1957), los low mimetic modes, asociados a las historias y biografías ficcionales de personajes ordinarios, se refieren a la vida cotidiana mientras que los high mimetic modes incitan a los lectores a percibir el texto tendencialmente más bien como epopeya monumental. En La Oculta, el horizonte de lo cercano y ordinario parece realmente experimentable por todos, a pesar de que los personajes pertenecen más bien a una clase social con cierto poder económico en el pasado ${ }^{10}$. Como Abad Faciolince (2018) ha dejado claro en una entrevista, los Ángel constituyen una familia común, típica de la clase media colombiana actual, con la que el propio autor dice de poder identificarse fácilmente. Debido a los aspectos autobiográficos del autor tratados en el texto, se puede hablar de un modelo de género en cercanía de la autoficción. El texto también sigue en ciertas ocasiones el modelo de la epopeya, de la que cobra autoridad, sin embargo, ubica la narración en un horizonte inmediato y concreto.

En cuanto al aspecto fundamental de las instancias narrativas, se puede afirmar que las técnicas aplicadas son decisivas para esta estrategia de ubicar el relato en una memoria inmediata y cotidiana. Mientras que García Márquez optaba por una instancia heterodiegética y auctorial -la authorial voice ubica lo narrado en el horizonte temporal lejano-, Abad Faciolince mezcla los fragmentos de tres narradores Yo y consigue, usando de nuevo la terminología de Lanser (1992), un tipo específico de personal voice desde distintas perspectivas. Los monólogos interiores de las tres voces homodiegéticas se ofrecen para este tipo de narraciones que articula experiencias vividas en un pasado cercano: "En realidad son monólogos en los que los

\footnotetext{
${ }^{10}$ Juristo denomina el relato incluso una "crónica de la decadencia de la oligarquía" (JURISTO, 2016, p. 110).
} 
personajes rememoran el pasado reciente y se integran en él" (FRAGERO GUERRA, 2018, p. 315). La facilidad de esta integración en el horizonte de lo experimentado se debe a la perspectiva narradora específica, en la que los narradores forman parte de la historia: "Por medio de las narraciones en yo, el texto literario conceptualiza la situación típica de comunicación de la memoria comunicativa, en la cual se añaden, a través del narrar, experiencias individuales y valoraciones subjetivas al tesoro colectivo de la experiencia" (ERLL, 2012, p. 236). La técnica de aplicar voces individuales provoca tanto una mayor autenticidad, puesto que los narradores se pueden considerar testigos de lo que narran, como también la posibilidad de ampliar lo recordado a una memoria colectiva:

El narrador l-as-witness que está en los testimonios presenciales y que asocia lo vivido con la observación de las experiencias de los otros, o el narrador autodiegético que hace pasar sus experiencias como paradigmáticas y que, por consiguiente, también habla para un colectivo, puede contribuir a la escenificación literaria de la función portadora que cumplen las memorias comunicativas en el texto literario. (ERLL, 2012, p. 236)

En consecuencia, los monólogos interiores se ligan a la representación del mundo interior y al aspecto mencionado de la focalización narrativa. En La Oculta se da el caso de que el texto realmente procesa "la percepción de hechos poniéndose en los zapatos de los que participaron en ellos -elementos que se convierten entonces en objetos típicos de las memorias comunicativas a través de la verbalización y la narración-" (ERLL, 2012, p. 238). El colectivo que se articula está formado por testigos directos de lo sucedido, en relación con la memoria comunicativa; gracias a la heterogeneidad de sus posiciones, puede ser representativo para muchos colombianos y sus pensamientos pueden ser fácilmente comprensibles para lectores contemporáneos. En consecuencia, se presentan los protagonistas también de una manera cómo se los imagina un lector de fuera a los miembros de la sociedad, lo que concede más autenticidad a lo narrado.

Por último, en "la representación espacial y temporal se hacen accesibles las transiciones del modo asociado con la experiencia al modo monumental” (ERLL, 2012, p. 239). Este aspecto favorece una comparación explícita con CAS. Mientras que la universalidad y atemporalidad del microcosmo Macondo le conceden una validez simbólica general, los datos exactos en La Oculta concretan lo narrado. A nivel de espacio, la finca es exactamente ubicable en el mapa y se encuentra entre Jericó y Palermo en el departamento de Antioquia. Parecido a Macondo, Jericó también está en alto grado recargado semánticamente y su nombre tiene ciertas connotaciones bíblicas, lo que lo relaciona con el modo monumenta ${ }^{11}$. No obstante, el municipio con algo más de trece mil habitantes tiene una conexión extratextual con la biografía del autor y es el lugar de nacimiento de Héctor Abad Gómez, padre del escritor. Se trata de un lugar realmente existente y en estrecha relación con la familia de Héctor Abad, linaje al que se alude en la novela cuando el protagonista Antonio menciona en sus excursiones sobre la genealogía de su familia a otro personaje del mismo nombre: "Antonio Abad, a quien le acabarían diciendo don Abad, patriarca casi legendario de Jericó, que fundaría otra estirpe de esas tierras" (ABAD

\footnotetext{
${ }^{11}$ El nombre del municipio colombiano, anteriormente Aldea de Piedra y Felicina, fue cambiado a Jericó por los pobladores del siglo XIX. La ciudad del mismo nombre, situada en Palestina a orillas del río Jordán, se menciona en los textos bíblicos y tiene un alto valor semántico en la tradición judeocristiana como el lugar donde los israelitas retornaron de la esclavitud en Egipto; además se proclama la ciudad más antigua del mundo. También Juristo (2016, p. 112) llama la atención sobre estas connotaciones y declara que además los padres ficcionales de los tres protagonistas cumplen una función familiar equiparable a José y María en la Biblia.
} 
FACIOLINCE, 2014, p. 189).

Con respecto a lo temporal, también se encuentran indicaciones explícitas de fechas y años, lo que concede más autenticidad e inmediatez a lo narrado. Por ejemplo, se menciona el 1994, año tanto de la muerte de Cobo, padre de los protagonistas, como del secuestro de su nieto Lucas (ABAD FACIOLINCE, 2014, p. 201). Estos acontecimientos se ubican en la narración en un pasado de algunos años, ya que el hoy de la narración se sitúa obviamente en el siglo XXI, más bien en la segunda década del milenio. Otras indicaciones importantes son las de los años 1840, en el que se inició la población de las montañas antioqueñas, y 1861, en el que los antepasados de los Ángel realmente empezaron a fundar La Oculta. El primer registro de las escrituras de la finca se realizó el 2 de diciembre de 1886 (ABAD FACIOLINCE, 2014, p. 41). Estas fechas fundacionales pertenecen al horizonte fuera de lo inmediato, ya traspasados los cien años máximos en los que se puede mantener la memoria comunicativa, y son tratadas en exclusiva por Antonio. Es curioso que Pilar, en cambio, no se interesa por sus antepasados en estas dimensiones temporales inaccesibles para ella. En vez de ello, tanto la primogénita como Eva refieren con frecuencia a los abuelos de los protagonistas a los que han conocido personalmente y que vivían a mediados del siglo XX. Así, los tres protagonistas mantienen distintas relaciones con los diferentes horizontes del pasado, o bien se interesan por lo ancestral como Antonio o bien reflexionan sobre el pasado cercano, tan traumático para Eva y Pilar (QUINTÍN-QUILEZ, 2019, p. 74). En resumen, se puede calcular que los acontecimientos que afectan a las dos hermanas han pasado en los últimos cien años y forman una memoria comunicativa al pasado reciente. Entonces, lo que resulta muy interesante en cuanto a este aspecto de generaciones es que se hacen notar realmente dos horizontes con un floating gap en medio, cuya línea es trazada por Antonio. Este protagonista, viviendo en el exilio y reflexionando detalladamente sobre la identidad colectiva tanto de su familia como de los demás habitantes de su zona de origen, se ocupa de escribir la prehistoria de su familia y mantiene la memoria cultural a la fundación del lugar ${ }^{12}$, mientras que los otros dos se ocupan de la realidad cotidiana y del pasado inmediato. En este sentido, no es sólo la dimensión del pasado reciente y experimentado lo que se trata sino también lo fundacional de la memoria cultural. Juristo hace hincapié en que la recurrencia literaria al mito y lo legendario resulta necesaria para la identidad de las grandes estirpes ilustres en el ámbito rural: "Pero la oligarquía rural [...] requiere una inmersión en el mito, o, por lo menos, una narración que contemple el rito obligado del secreto ancestral, de los débitos de sangre, de antiguas venganzas o penas de amor no resueltas a pesar del paso de las generaciones" (JURISTO, 2016, p. 110). Este detalle importante causa que también La Oculta oscila entre ambas dimensiones, la mítica memoria cultural y la memoria comunicativa, con sus modos narrativos respectivos, y hace notar la compleja tensión dialéctica entre los horizontes de lo ancestral épico y lo contemporánea de la memoria comunicativa en que se articula el relato.

En resumen, los resultados, en cuanto al conjunto de los nueve criterios, muestran que el relato tiende hacia el modo asociado con la experiencia, que "se caracteriza por tener formas literarias que sugieren la sujeción a la cotidianidad, la especificidad semántica de la experiencia y la autenticidad" (ERLL, 2012, p. 239).

\footnotetext{
${ }^{12}$ Juristo explica por qué tiene que ser efectivamente Antonio quien se ocupa de la crónica de lo remoto: "Antonio es necesariamente el cronista de la historia, y no sólo por su condición de homosexual, que lo obliga ya a ser distinto y a no poder aceptar la tradición, sino por su capacidad de emprendimiento" (JURISTO, 2016, p. 113). Una razón para la necesidad de un papel activa en la cultivación de la memoria cultural es el hecho de que Antonio es el único hijo masculino del que su padre esperaba que siguiera con la tradición y heredara el apellido a las futuras generaciones, no obstante, el mismo sabe que será el último de la estirpe.
} 
Debido a que domina la representación del pasado a través de experiencias de figuras concretas y representativas para la sociedad colombiana contemporánea, en el ámbito de la memoria individual autobiográfica, se relaciona lo narrado con lo inmediato y con la figura del autor. Esto corresponde a las nuevas tendencias en la literatura latinoamericana, en la que se puede observar en general una despedida de los modelos épicos, todavía característicos para las obras fundadoras de identidad publicadas durante el boom (MÜLLER, 2004). Desde finales del siglo XX, la ficcionalización del Yo co una estrategia aplicada con frecuencia para conceder mayor veracidad a las obras literarias (CAPOTE, 2019, p. 36). La sensación de que se trata de experiencias realmente vividas convierte las narraciones en medios relevantes de una memoria comunicativa, caracterizados por su destacada autenticidad e inmediatez. Así, La Oculta constituye un buen ejemplo de esta nueva "literatura preocupada por lo inmediato" (CAMACHO DELGADO, 2008, p. 314).

Así, se ubican los elementos narrados, aunque algunos procedan de mucho tiempo atrás, en el horizonte próximo de percepción. Se evidencia en qué medida ambos horizontes del pasado exigen, para ser recordados, una relevancia para el presente. La historia ajena da una identidad a los miembros de la familia, procedentes de pobladores con raíces judías que montaron esta finca cuya existencia es el resultado valeroso del trabajo de sus antepasados. La relevancia del pasado reciente queda obvia en el hecho de que el estado actual y los recuerdos personales influyen en la decisión sobre qué hacer con la finca. Esta mezcla entre ambas dimensiones es clave para comprender las estrategias retóricas aplicadas en ambas novelas, con respecto al tratamiento de una memoria colectiva. Se puede notar incluso una transición de los contenidos de la memoria narrados, de una a la otra de las dimensiones descritas. El relato de CAS lleva lo cotidiano a la épica remota, cumpliendo esta novela así "el deseo de fundar un mito latinoamericano" (GONZÁLEZ ECHEVARRÍA, 2000, p. 48). En el relato de La Oculta, lo legendario se transfiere a la actualidad, por lo que sólo se eligen los elementos identitarios del pasado ancestral que son imprescindibles para entender los pensamientos de los que recuerdan el pasado reciente, con el fin de poder tomar su decisión sobre cómo seguir en el futuro.

En conclusión, gracias a aplicar mayoritariamente el modo monumental en CAS, se generalizaban las distintas memorias y experiencias recordadas en un horizonte temporal y espacial lejano, creando esta novela total una identidad cultural de todos latinoamericanos. La Oculta también remite al mito, no obstante, Héctor Abad ubica la narración en un horizonte cercano y concreto, causando de tal manera el efecto de poder crear una sensación de cierta veracidad histórica, por haber experimentado los protagonistas los acontecimientos. La verosimilitud realista se hace notar incluso cuando la narración refiere a hechos fuera del horizonte temporal de los cien años máximos de la memoria comunicativa, al relatar detalladamente el mito de la población de las montañas en el siglo XIX.

En resumen, se puede observar una evolución desde lo mítico a lo contemporáneo y cotidiano, vinculado a la experiencia directa y la autenticidad de lo relatado. Esto corresponde a la tendencia general de alejarse de la épica en la nueva literatura latinoamericana y subrayar, en vez de lo fundador de una identidad específicamente latinoamericana, lo ordinario y rudo de la realidad en las grandes urbes del siglo XXI. Este último aspecto se nota en La Oculta algo menos, ya que el relato se centra más en la vida del campo para describir los modos de vivir tradicionales en la naturaleza americana, a través de emplear elementos de flora y fauna autóctona con una alta carga semántica. De esta manera, también se podría considerar identitaria, ofreciendo algo exótico para el mercado global, sin embargo, esto no ocurre en la misma medida como en Cien años de Soledad, novela con que guarda, sin duda alguna, unas 
similitudes decisivas.

\section{Referencias}

ABAD FACIOLINCE H. Basura. Madrid: Lengua de Trapo, 2000.

ABAD FACIOLINCE H. El olvido que seremos. Bogotá: Planeta, 2006.

ABAD FACIOLINCE H. La Oculta. Bogotá: Penguin Random House, 2014.

ABAD FACIOLINCE H. La Oculta. Traducción de Peter Kultzen. Berlín: Berenberg, 2018.

ABAD FACIOLINCE H.; PARKIN DANIELS J. Héctor Abad: 'Do not sink into rancour'. Entrevista. The Guardian, 7 de octubre 2018. Disponible en: <https://www.theguardian.com/books/2018/oct/06/hector-abad-the-farm-colombia-booksinterview>. Acceso: 17 de mayo 2020.

ASSMANN A. Cultural memory and Western civilization: functions, media, archives. Cambridge: Cambridge University Press, 2011.

ASSMANN J. Historia y mito en el mundo antiguo: los orígenes culturales de Egipto, Israel y Grecia. Madrid: Gredos, 2011.

BELL-VILLADA G. Garcia Marquez and the Novel. Latin American Literary Review, v. 13, número 25, pp. 15-23, 1985.

CAMACHO DELGADO, J. M. La narrativa colombiana contemporánea: magia, violencia y narcotráfico. En: BARRERA T. Historia de la literatura hispanoamericana. Vol. 3: Siglo XX. Madrid: Cátedra, 2008.

CAPOTE V. Narrativas del yo, intertextualidades y parodias. Las dinámicas de la edición global. En: QUESADA, C.; VANDEN BERGHE, K. El libro y la vida: Ensayos críticos sobre la obra de Héctor Abad Faciolince. Lieja: Presses universitaires de Liège, 2019.

DE TORO, A. Los laberintos del tiempo: temporalidad y narración como estrategia textual y lectoral en la novela contemporánea. Fráncfort: Vervuert, 1992.

DÜSDIEKER, K. Kulturtransfer, Renarrativierung, InterAmerika: Gabriel García Márquez als Mittler zwischen latein- und nordamerikanischem Roman. Berlín: Wiss. Verl. Berlin, 1999.

ERLL, A. Memoria colectiva y culturas del recuerdo: estudio introductorio. Bogotá: Universidad de los Andes, 2012.

ERLL, A. Gedächtnisromane: Literatur über den Ersten Weltkrieg als Medium englischer und deutscher Erinnerungskulturen in den 1920er Jahren. Trier: WVT, 2003.

ESPOSITO, E. Social Forgetting: A Systems-Theory Approach. En: ERLL, A. A companion to cultural memory studies. Berlín / Nueva York: De Gruyter, 2010.

FRAGERO GUERRA, C. La Oculta (2014) de Héctor Abad Faciolince: situaciones narrativas y oralidad. Anales de Literatura Hispanoamericana, número 47, pp. 313-326, 2018.

FRYE, N. Anatomy of Criticism: Four Essays. Princeton: Princeton University Press, 1957.

GARCÍA DE LA CONCHA, V. Gabriel García Márquez, en busca de la verdad poética. En: 
GARCÍA MÁRQUEZ: Cien años de soledad. Ed. Conmemorativa. Madrid: Real Acad. Española, pp. LIX-XCV, 2007.

GARCÍA MÁRQUEZ, G. Cien años de soledad. Edición Conmemorativa. Madrid: Real Academia Española, 2007.

GERLING, V. Cien años de soledad y las falsedades de la historiografía. En: TRANS-, número 7, pp. 1-12, 2009.

GOETSCH, P. Vorwort. En: ; ERZGRÄBER, W. Mündliches Erzählen im Alltag, fingiertes mündliches Erzählen in der Literatur. Tubinga: Narr, 1987.

GONZÁlEZ ECHEVARRÍA, R. Cien años de soledad: The Novel as Myth and Archive. In: MLN, v. 99, número 2, Hispanic Issue (Mar.), pp. 358-380, 2000.

HARTWIG, S. Einführung in die Literatur- und Kulturwissenschaft Lateinamerikas: Schwerpunkt Hispanoamerika. Stuttgart: Metzler, 2018.

HOMANN, F. Macondo como lugar de la memoria y medio del recuerdo colectivo, entre memoria comunicativa y memoria cultural en Cien años de soledad de Gabriel García Márquez. En: DÍAZ PÉREZ, O.; RENNER, R.; TORRES, V.; BARRAGÁN CABRAL, A.: Literatura y cine como medios del recuerdo y de la memoria. Berlín: Peter Lang, forthcoming.

JURISTO, J.A. El léxico de la tribu. Cuadernos hispanoamericanos, número 778, pp. 110-113, 2016.

LACHMANN, R. Gedächtnis und Literatur: Intertextualität in der russischen Moderne. Francfort: Suhrkamp, 1990.

LANSER, S. Fictions of Authority: Women Writers and Narrative Voice. Ithaca: Cornell University Press, 1992.

MÜlleR, G. Boom-Autoren heute: García Márquez, Fuentes, Vargas Llosa, Donoso und ihr Abschied von den großen identitätsstiftenden Entwürfen. Francfort: Vervuert, 2004.

NEUMANN, B. Erinnerung - Identität - Narration. Gattungstypologie und Funktionen kanadischer fictions of memory. Berlín / Nueva York: de Gruyter, 2005.

QUINTÍN-QUILEZ, P. La herencia como símbolo de las relaciones familiares en La Oculta, novela de Héctor Abad Faciolince. Revista de Antropología y Sociología: VIRAJES, número 21 (1), pp. 59-81, 2019.

RIGNEY, A. The Dynamics of Remembrance: Texts between Monumentality and Morphing. En: Astrid Erll: A companion to cultural memory studies. Berlín / Nueva York: De Gruyter, 2010.

SIEBENMANN, G. Gabriel García Márquez: zwischen magischem Realismus und politischem Engagement. Schweizer Monatshefte: Zeitschrift für Politik, Wirtschaft, Kultur, número 69, pp. 55-67, 1989.

WEHR, C. Mythisches Erzählen und historische Erfahrung. Strategien der Geschichtsbewältigung in Gabriel García Márquez' Cien años de soledad. Romanistisches Jahrbuch, número 54, pp. 380-404, 2003.

Recebido em: 17/05/2020

Aceito em: 13/07/2020 